\title{
Optimization study of the unmanned craft's propulsion and intelligent control system based on simulated analysis
}

\author{
Hong-Xiang $\mathrm{Si}^{1, a}$,Song-Lin Yang ${ }^{2, b}$, Song Pan ${ }^{3, \mathrm{c}}$ \\ 1,2,3 Jiangsu University of Science and Technology \\ Naval Architecture and Marine Engineering Department \\ Zhengjiang, Jiangsu 212003, China \\ a497940497@qq.com, bysl560516@vip.163.com, '804198382@qq.com
}

Keywords: High-speed mono-hull USV; intelligent propulsion; genetic algorithm; simulation;

\begin{abstract}
In order to increase the real-time process optimization, this paper proposes an online simulation based on unmanned CPP Propulsion intelligent control and system optimization method, mathematics model of adjustable pitch propeller is established, then based on MATLAB platform, using the simulation software simulation to establish a simulation model, and using the look-up table fuzzy controller to actualize the intelligent propulsion control of unmanned boat. Then, the mathematical model of the systematic optimization is established. Based on the simulation model, the optimization design of the system is realized by using the genetic algorithm toolbox GAOT of MATLAB. Finally, a numerical example is given. The calculation results show that the accuracy and reliability of simulation and optimization are both good, and the method is effective and feasible.
\end{abstract}

\section{Introduction}

Since the 21 st century, the intelligent unmanned vehicle entered the new period of rapid development. In 2001, the United States department of the navy officially put forward the plan to build the littoral combat ship. In this plan, it is clearly put up that to establish unmanned combat system which is composed of high speed unmanned craft, unmanned aerial vehicle, unmanned ground vehicles and unmanned submarine to complete the mission such as investigation, detecting, alert and conducting anti-submarine warfare to cooperate with special operations.

There are usually two ways of optimization study, including off-line and on-line. Off-line optimization is usually specific to a optimization problem. Firstly, it is according to the conventional train of thought,then determining the design variables, target function and restraint conditions, then writing optimization program. After the optimization program execution, we can achieve optimization result. The emergence of modern simulation technology can be repeatedly test and run on the computer to replace the costly physical simulation and physical experiment. It has many outstanding advantages. It is generalized and applied to all the aspects of the ship domain.

In recent years, many papers on optimization and simulation research has been published at home and abroad. But I didn't retrieve papers that studying on-line optimization which combines marine simulation with optimization.In the field of Marine engineering, USV is also a research hot-spot. So I choose this type of ship, and research the online optimization problems based on the simulation.

\section{Mathematical Model of Propeller Propulsion}

\section{A. Unmanned Craft Resistance}

The resistance of the unmanned craft is composed of 2 parts, including the frictional resistance and the remaining resistance. Based on the transformation of the mother ship, the calculation is carried out on the software Maxsurf. In this paper, the relationship the resistance and speed is fitting, for each speed, we can get the ship's resistance in real time. 


\section{B. Adjustable Propeller Propulsion System}

Thrust coefficient: $K_{T}=\frac{T_{P}}{\rho n^{2} D^{4}}$

Torque coefficient: $K_{Q}=\frac{M_{p}}{\rho n^{2} D^{5}}$.

Propeller open water efficiency: $\eta_{0}=K_{T} J / \rho / \rho 2_{Q}$.

Feed speed: $V_{A}=(1-\omega) V_{S}$.

Inlet velocity coefficient: $J=V_{A} / n D$.

Type: $T, Q$ respectively correspond to single propeller's thrust and torque; $\omega$ is wake fraction; $P$ is the density of water; $D$ is the diameter of a propeller; $n$ is propeller's speed; $t$ is thrust deduction fraction for the speed of the ship.

$$
\begin{aligned}
& 10 K_{Q}=\sum_{i=0}^{n 1} \sum_{j=0}^{n 2} \sum_{k=0}^{n 3} B_{i j k}(P / D)^{i}(J)^{j}\left(A_{E} / A_{0}\right)^{k} . \\
& K_{T}=\sum_{i=0}^{n 1} \sum_{j=0}^{n 2} \sum_{k=0}^{n 3} A_{i j k}(P / D)^{i}(J)^{j}\left(A_{E} / A_{0}\right)^{k} .
\end{aligned}
$$

Among them, $A_{i j k}, B_{i j k}$ are the regression coefficient of the corresponding propeller. When in use, it is only needed to meet the identified $Z, P / D, J$, check the corresponding table, and substitute the data into the formula then $K_{T}$ and $K_{Q}$ can be obtained.

\section{Simulation Model}

The simulation model is carried out based on 2 dynamic equations (translation equation and rotation equation).

\section{A. Translation Equation}

$$
(m+\Delta m) \frac{d V_{s}}{d t}=T_{e}-R_{t} .
$$

Where $\mathrm{m}$ is the quality of hull, $\Delta m$ is the added mass, $V_{s}$ is the speed of ship; $T_{e}$ is the effective thrust of propeller, $R_{t}$ is the total resistance of the ship.

\section{B. Rotational equation}

$$
2 \pi I \frac{d n}{d t}=M_{d}-M_{p}
$$

Where $I$ is moment of inertia of propeller, $M_{d}$ is propeller's torque provided by main engine, $M_{p}$ is the water resistance torque acting on propeller, $N$ is the rotate speed of propeller.

\section{Look-Up Table of Fuzzy Control}

This paper selects the conventional two-dimensional fuzzy controller. The input variables are speed deviation $E$ and deviation change $\Delta E$. The output variables are the adjustable-pitch screw propulsion for the wave-piercing catamaran. It uses double fuzzy control, while one control speed $n$ 
and the other control the pitch $P$, so $U$ stands for both of them.

\section{Optimization mathematical model}

\section{A. design variables}

The parameter selection for the Intelligent propulsion system(which adopts the Adjustable pitch) of the high speed unmanned vessel include: design speed $V_{0}$, propeller diameter $D$, disk ratio $A_{E} / A_{0}$, the three proportionality coefficient $K_{1}, K_{2}, K_{3}$ for speed $\mathrm{n}$ controlling of the fuzzy controller , the three proportionality coefficient $K_{4}, K_{5}, K_{6}$ for pitch $P$ controlling of the fuzzy controller, 9 parameters in total. We design the variables based on these 9 parameters, its vector expression is as follow:

$$
X_{T}=\left\{V_{0}, D, A_{E} / A_{0}, K_{1}, K_{2}, K_{3}, K_{4}, K_{5}, K_{6}\right\}
$$

\section{B. Constraint Condition}

\section{1) Designing Variables' Range}

The scope of upper and lower limit of the parameters includes the target speed $V_{0}$, the propeller diameter $D_{0}$, the disk ratio $A_{E} / A_{0}$, three parameters of the fuzzy controller to control the rotational speed $K_{1}, K_{2}, K_{3}$, and three parameters of fuzzy controller to control the pitch $\mathrm{P} K_{4}, K_{5}, K_{6}$. 2) Propeller Design Meets the requirem $\mathrm{e}^{\mathrm{nt}}$ of cavitation. The Keller equation is as follow:

$$
\frac{1.3+0.3 Z}{\left(P_{0}-P_{V}\right) D^{2}} T-\frac{A_{E}}{A_{0}} \leq 0
$$

Where $P_{0}$ is static pressure at the center of propeller shaft, $P_{V}$ is the vaporization pressure of water at the temperature of $15, T$ is the thrust force of propeller, $Z$ is the number of propeller blades.

3) The restriction of the propulsion system equation according to translation equation (1) and rotary equation (2).

\section{Genetic algorithm toolbox (GAOT) and the concrete realization of the optimization problem of the system}

Genetic algorithm toolbox GAOT includes a number of practical functions. According to the function, these functions can be divided into : the main interface function, initialization function, the selection function, exchange function, the variation function, the termination function, binary representation function.

The fitness function and main program are written on MATLAB platform. When the main program is written, the upper and lower limits of each design variable, the selection method, the population number, and the genetic algebra are determined.

Mathematics model and genetic algorithm toolbox GAOT correspondence is as follows:

Gene: $V_{0}, D, A_{E} / A_{0}, K_{1}, K_{2}, K_{3}, K_{4}, K_{5}$ and $K_{6}$ correspond to the design variables in the optimized mathematical model.

Chromosomes: a real number coded string of $\left\{V_{0}, D, A_{E} / A_{0}, K_{1}, K_{2}, K_{3}, K_{4}, K_{5}, K_{6}\right\}$, that is, a combination corresponding to a design variable.

Population size: when design variables are large, taking a large value is favorable, this can reduce the probability of the program into a local optimization. But it can not get too large, otherwise it will waste a lot of computer memory resources.

Genetic Algebra: Theoretically, the more genetic algebra the better, but it also needs to take the time savings into account.

Fitness function: 


$$
f(X)=-F_{1}(X)^{\frac{9}{7}} \times F_{2}(X)^{\frac{7}{9}} .
$$

Corresponding to the inverse of the objective function in the mathematical model.

The optimizer calls the simulation model with the following statement:

$[\mathrm{T}, \mathrm{xx}, \mathrm{y}]=\operatorname{sim}$ ('simulation model name', [simulation start time simulation termination time])

\section{Examples and Analysis}

\section{A. Principal Dimensions and Ranges of Variable Parameter}

The principal dimensions of the 100T unmanned ship that this paper choose are shown in table 1 . The scope of design variables are shown in table 2 . The optimization results shown in table 3 .

Table 1. The Principle Dimension of 84T Unmanned Ship

\begin{tabular}{|c|c|c|c|c|c|c|c|c|c|}
\hline $\begin{array}{c}\text { Design } \\
\text { Variables }\end{array}$ & $\mathrm{V}_{0} / \mathrm{kn}$ & $\mathrm{D} / \mathrm{m}$ & $\mathrm{A}_{\mathrm{E}} / \mathrm{A}_{0}$ & $\mathrm{~K}_{1}$ & $\mathrm{~K}_{2}$ & $\mathrm{~K}_{3}$ & $\mathrm{~K}_{4}$ & $\mathrm{~K}_{5}$ & $\mathrm{~K}_{6}$ \\
\hline $\begin{array}{c}\text { Optimization } \\
\text { Results }\end{array}$ & 30.09 & 1.098 & 0.627 & 0.237 & 0.099 & 0.029 & 0.598 & 0.567 & 0.097 \\
\hline
\end{tabular}

Table 2. Design Variable Range of 100t Unmanned Ship

\begin{tabular}{cccccccccc}
\hline $\begin{array}{c}\text { Design } \\
\text { Variables }\end{array}$ & $\mathrm{V}_{0}$ & $\mathrm{D}$ & $\mathrm{A}_{\mathrm{E}} /$ & $\mathrm{K}_{1}$ & $\mathrm{~K}_{2}$ & $\mathrm{~K}_{3}$ & $\mathrm{~K}_{4}$ & $\mathrm{~K}_{5}$ & $\mathrm{~K}_{6}$ \\
\hline $\begin{array}{c}\text { lower } \\
\text { limit }\end{array}$ & 30 & 0.8 & 0.6 & 0.05 & 0.001 & 0.008 & 0.4 & 0.4 & 0.05 \\
\hline $\begin{array}{c}\text { upper } \\
\text { limit }\end{array}$ & 32 & 1.1 & 0.8 & 0.25 & 0.1 & 0.03 & 0.6 & 0.6 & 0.1 \\
\hline
\end{tabular}

Table 3. Optimization Results

\begin{tabular}{cccc}
\hline Designed Length L/m & Width B/m & $\begin{array}{c}\text { Designed Draught } \\
\mathrm{d} / \mathrm{m}\end{array}$ & $\begin{array}{c}\text { Displacement } \\
\Delta / \mathrm{t}\end{array}$ \\
\hline 7.55 & 3.61 & 0.42 & 84 \\
\hline
\end{tabular}

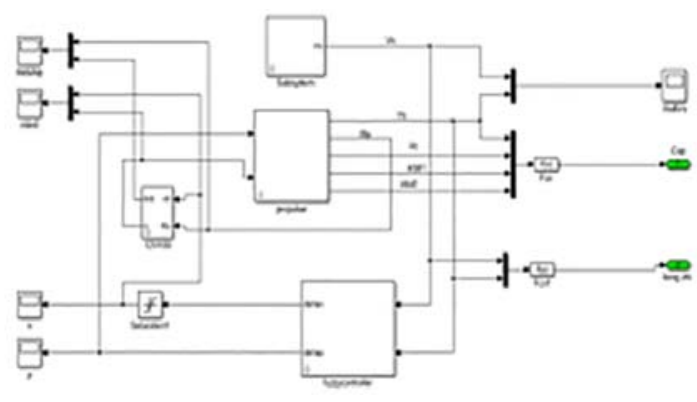

Figure 1 Propulsion and total control system model

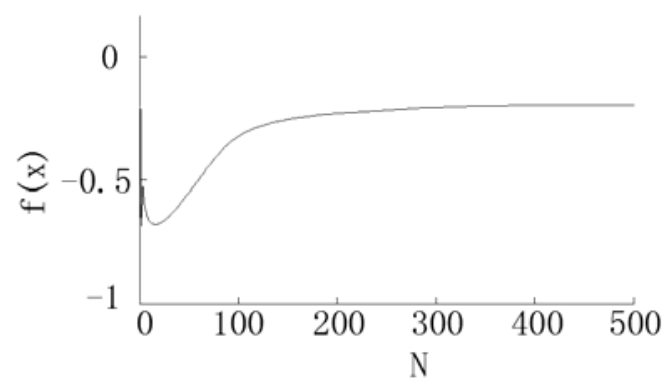

Figure 2 The Variation of Fitness Function Value with Genetic Algebra

Since the demihulls of the catamaran is far away from the other, its wake fraction is low. Take the wake fraction $\omega=0.03$. Take the thrust deduction fraction of the propeller $t=0.02$ and take the 
number of the propeller blade $Z=5$. Propulsion and total control system model is established based on Simulink and the model is shown in figure 1.

After the application finishes its run, the optimization results that is obtained is shown in table 3. Figure 2 shows the variation of the fitness function value $f(x)$ with the genetic algebra $N$, and the maximum fitness value can be obtained is -0.1962 . The fitness function value increases rapidly when genetic algebra is between 1-300. When the genetic algebra exceed 300, changes in fitness function value occur slowly and the value is basically a horizontal line. This result reflects that genetic algorithm has a characteristic of the fast convergence and it has a good adaptability and high efficiency for solving optimization problems.

\section{B. The effects of initial speed}

In order to know the influence of initial speed on the optimization results, we keep all the other design variables at their default values and the propulsion control of the high-speed mono-hull USV in condition of no turbulence. We need to set the initial population number equals to 100, the initial pitch $\mathrm{V}$ equals to $0.7 \mathrm{~m}$, the initial speed equals to $29 \mathrm{kn}, 31 \mathrm{kn}, 31.5 \mathrm{kn}, 32 \mathrm{kn}, 33 \mathrm{kn}, 33.5 \mathrm{kn}$, and then make a comparative study on these 6 kinds of optimization results.

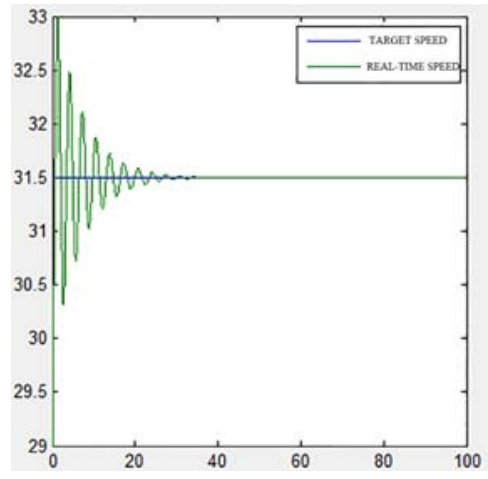

Figure $3.1 \mathrm{~V}=29 \mathrm{kn}$

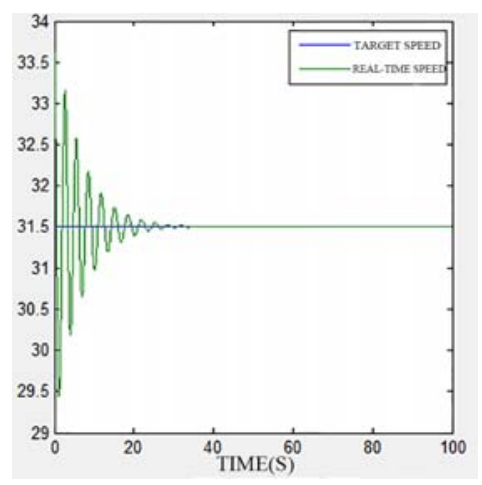

Figure $3.3 \mathrm{~V}=31.5 \mathrm{kn}$

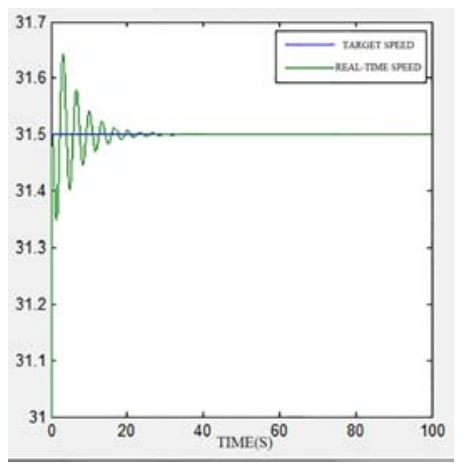

Figure $3.5 \mathrm{~V}=33 \mathrm{kn}$

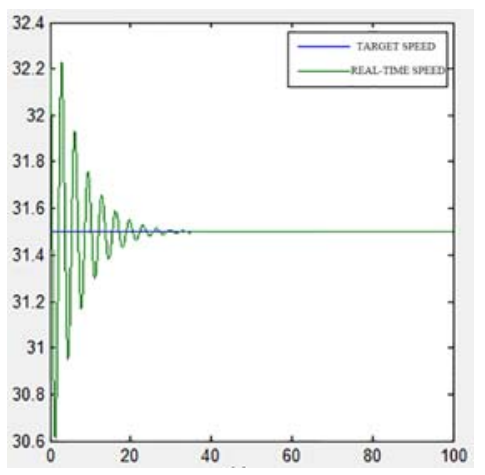

Figure $3.2 \mathrm{~V}=31 \mathrm{kn}$

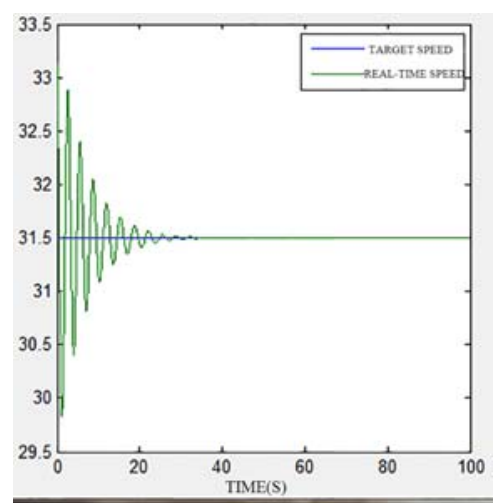

Figure $3.4 \mathrm{~V}=32 \mathrm{kn}$

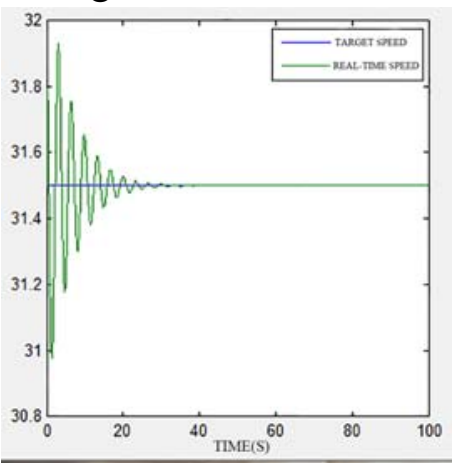

Figure $3.6 \mathrm{~V}=33.5 \mathrm{kn}$ 
In order to know the influence of initial speed on the optimization results, we keep all the other design variables at their default values and set the initial population number equals to 100 . To Set the initial speed $\mathrm{V}$ equal to $29 \mathrm{kn}, 31 \mathrm{kn}, 31.5 \mathrm{kn}, 32 \mathrm{kn}, 33 \mathrm{kn}$ and $33.5 \mathrm{kn}$ and then do a comparative study on these 6 kinds of optimization results. The optimization results are as follows:

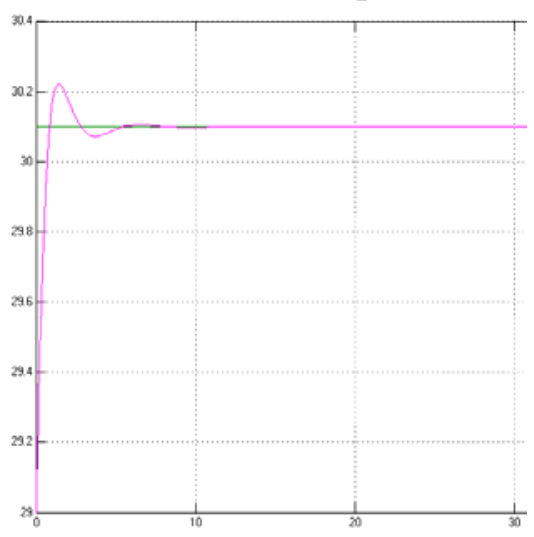

Figure $4.1 \mathrm{~V}=29 \mathrm{kn}$

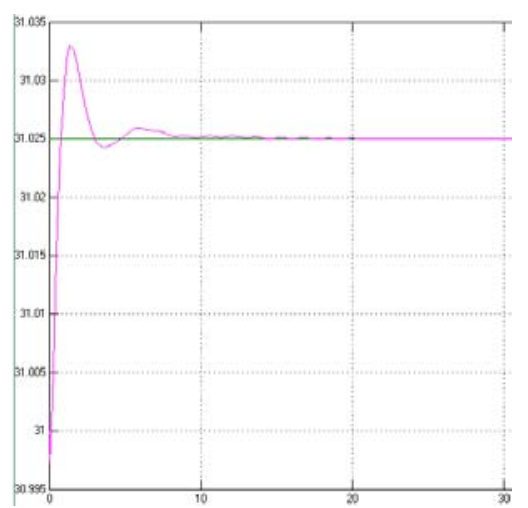

Figure $4.3 \mathrm{~V}=31.5 \mathrm{kn}$

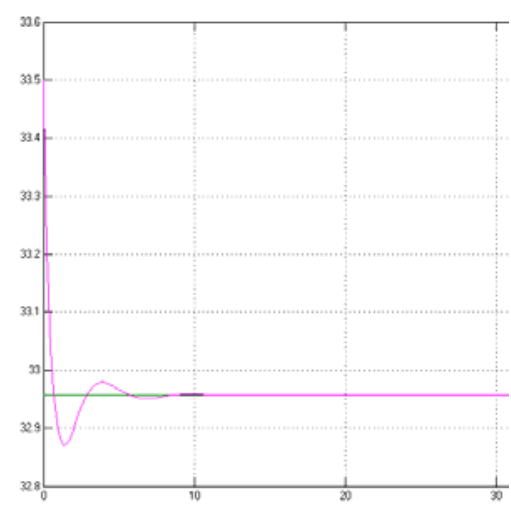

Figure $4.5 \mathrm{~V}=33 \mathrm{kn}$

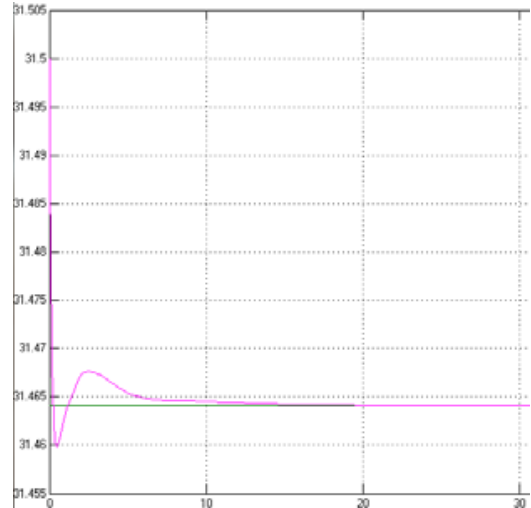

Figure $4.2 \mathrm{~V}=31 \mathrm{kn}$

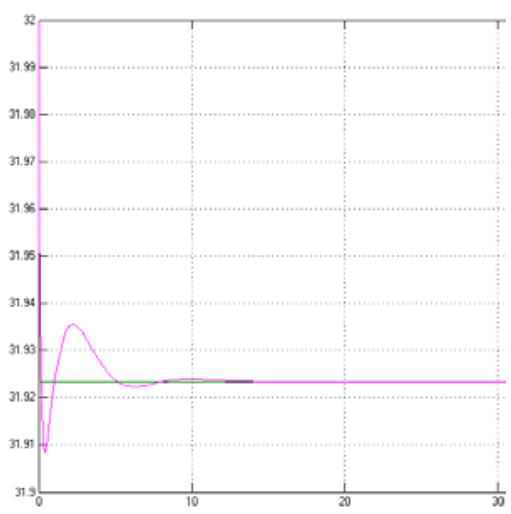

Figure $4.4 \mathrm{~V}=32 \mathrm{kn}$

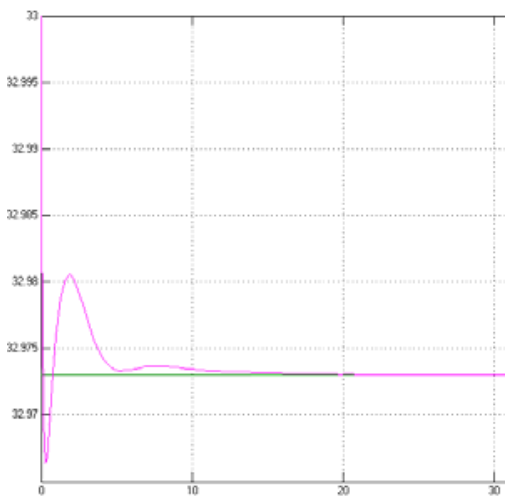

Figure $4.6 \mathrm{~V}=32.5 \mathrm{kn}$ 
Table 4. Comparison of Results Before and After Optimization

\begin{tabular}{|c|l|c|c|}
\hline Initial speed $(\mathrm{kn})$ & Optimization & Speed overshoot $(\mathrm{kn})$ & Settling time $(\mathrm{s})$ \\
\hline \multirow{2}{*}{29} & after & 0.20 & 20 \\
\cline { 2 - 4 } & before & 1.50 & 40 \\
\hline \multirow{2}{*}{31} & after & 0.003 & 28 \\
\cline { 2 - 4 } & before & 0.40 & 45 \\
\hline \multirow{2}{*}{31.5} & after & 0.05 & 35 \\
\cline { 2 - 4 } & before & 0.15 & 37 \\
\hline \multirow{2}{*}{32} & after & 0.08 & 20 \\
\cline { 2 - 4 } & before & 0.70 & 37 \\
\hline \multirow{3}{*}{33} & After & 0.025 & 36 \\
\cline { 2 - 4 } & before & 1.70 & 20 \\
\hline \multirow{2}{*}{33.5} & after & 0.50 & 38 \\
\cline { 2 - 4 } & before & 1.40 & \\
\hline \multirow{2}{*}{33} & & & 36 \\
\hline
\end{tabular}

When the independent variable is initial speed, the contrast of the results before and after optimization is shown in table 4. Comparing the optimization result between the former and the after, the following conclusions can be obtained:

The overshoot of the speed of fuzzy control system with adjustable pitch(without any optimization) is very large. But the value decreases obviously after the optimization. The minimum value of the speed overshoot before optimization is obtained when the initial speed is $31.5 \mathrm{kn}$. The time required to reach the target speed before and after optimization is different. In general, the optimized control system has advantages of small overshoot and short settling time. The optimum effects are even more dramatic. When the speed is greater than the optimal value, the settling time is basically the same.

\section{Conclusion}

The propulsion control system and system optimization method of the wave-piercing catamaran based on online simulation overall consider the resistance propulsive performance speed ability and control feature of the wave- piercing catamaran. Ship is a giant system. Except the performances above, there are a lot of other performances, including dirigibility and seakeeping. It should further studied to consider the ship performances overall and making the ship system comprehensive optimization based on online emulation come true.

\section{References}

[1] J.González,S.Gomáriz, "Fuzzy controller for the yaw and velocity control of the Guanay II AUV," IFAC-Papers OnLine, vol. 48, Dec. 2015, pp. 268-273, doi: 10.1016/j.ifacol.2015. 06. 044.

[2] Hossein Faraji, Farsam Farzadpour, "Intelligent position control of slider- crank mechanism in the ship's propeller,” AI \& Robotics and 5th Robo Cup Iran Open International Symposium (RI OS), IEEE Press, Apr.2013, pp. 1-7, doi: 10.1109/RIOS.2013.6595307.

[3] Jing Dai. Research of Intelligent Control Technology for Marine Azimuth Thruster[D]. Wu Han: The Second Ship Design Institute, 2012.

[4] Jia-liang Li, "Development and Application of Unmanned Surface Vehicle," Fire Control \&Command Control, vol. 37, Jun. 2012, pp. 1249-1253, doi: 1002-0640(2012) 06-0203-05.

[5] Guo Chen, "Researches on Fault Diagnosis of Ship Propulsion System Based on T-S Fuzzy Model,’Ship Engineering, vol. 37, Jul. 2015, pp. 59-63,doi:10.13788/j.cnki.cbgc.2015.07.059. 